\title{
Ventilation despite an endotracheal tube kink!
}

Editor, A 24 year old ASA 1 patient with limited mouth opening was posted for elective maxillo-facial surgery. Awake fibre-optic nasal intubation was planned after upper airway anaesthesia and mild sedation. A prewarmed (for tube softening to make it atraumatic), well lubricated $7 \mathrm{~mm}$ cuffed portex endotracheal tube was mounted on the fibre-optic device and inserted after adequate nasal preparation.. On visualization of the vocal cords and tracheal rings through the fibre-optic bronchoscope, the pre-mounted endotracheal tube (ETT) was gently pushed into the trachea and cuff inflated. Following removal of the fibre-optic bronchoscope, the tube was connected to the anaesthesia circuit and bilateral air entry was checked. Air entry was decreased in the bases, but normal in the apices. Airway pressure was in the upper limits of normal and oxygen saturation was $100 \%$. Immediately, fibre-optic bronchoscope was re-inserted through the ETT. On examination, the tube had taken an acute bend on the concave side, at a point just below the cuff, opposite the mid-point of the circumference of the Murphy eye. The bend of the tube was sitting just over the vocal cords with the Murphy eye opening plunging into the glottis. Technically, the patient was getting ventilated through the opening of the Murphy eye. The bevel of the tube was facing upwards, away from the cords.

Immediately, the kinked ETT was removed under vision and a fresh cuffed ETT was inserted through a repeat nasal fibre-optic bronchoscopy. After confirming bilateral air entry and normal capnography, patient was given a standard general anesthesia. Thereafter the patient was ventilated without any problems and the entire perioperative course was uneventful.

The first inserted ETT would have become very soft, ${ }^{1}$ as it was pre-warmed and would have kinked and got displaced after removal of the fibre-optic device. But the site of the kink and the way the patient was getting ventilated was uncommon. It was a unique situation wherein the patient was getting oxygenated through the Murphy eye in spite of the kinked ETT. A high degree of suspicion along with prompt action to replace the ETT was pertinent in maintaining the airway in this case. There are several reports of tube kink $^{2,3}$ at various points along the ETT. Usually in such cases, there is increased airway pressure along with inability to ventilate the patient, decreased air entry and obstruction to insertion of suction catheter beyond the point of kink. ${ }^{4}$ The role of Murphy eye $e^{5}$ itself is to serve as an alternative portal of ventilation in the design of the tracheal tube. This case highlights that any part of the tube can get kinked, which has to be quickly diagnosed and corrected.

U Hariharan, N Baduni, BP Singh. Department of Anaesthesia and Intensive care ESI Hospital and Dental College, Rohini, New Delhi, India.

\section{References}

1. Ayala JL, Coe A. Thermal softening of tracheal tubes. $\mathrm{Br} J$ Anesth 1997;4:543-5. http://dx.doi.org/10.1093/bja/79.4.543

2. Hübler, M; Petrasch, F. Intraoperative Kinking of Polyvinyl Endotracheal Tubes. Anesth Analg.2006,103;6:1601-1602. http://dx.doi.org/10.1213/01.ane.01000246275 $.01903 .2 \mathrm{c}$

3. Hariharan U, Garg R, Sood R, Goel SR. Intraoperative kinking of the intraoral portion of an endotracheal tube. J Anaesthesiol Clin Pharmacol.2011;27:290-1. http://dx.doi.org/10.4103/0970-9185.81855

4. Prakash S, Kumar A, Kumar M, Gogia AR. Successful detection and management of kinked tracheal tube in a patient with severe post-burn contracture of the neck. Indian $J$ Anaesth.2013;57:90-1. http://dx.doi.org/10.4103/0019-5049.108587

5. Murphy FJ. Two improved intratracheal catheters. Anesth Analg 1941;20:102-5. http://dx.doi.org/10.1213/00000539194101000-00022 